\title{
The Impact of Carbon Nanofibres on the Interfacial Properties of CFRPs Produced with Sized Carbon Fibres
}

\author{
Zhenxue Zhang ${ }^{1, *}{ }^{\infty}$, Xiaoying $\mathrm{Li}^{1}{ }^{1}$, Simon Jestin ${ }^{2}$, Stefania Termine ${ }^{3}$, Aikaterini-Flora Trompeta ${ }^{3}{ }^{(}$,

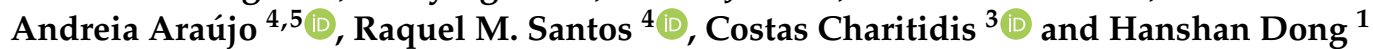

check for

updates

Citation: Zhang, Z.; Li, X.; Jestin, S.; Termine, S.; Trompeta, A.-F.;

Araújo, A.; Santos, R.M.;

Charitidis, C.; Dong, H. The Impact of

Carbon Nanofibres on the Interfacial

Properties of CFRPs Produced with

Sized Carbon Fibres. Polymers 2021,

13, 3457. https://doi.org/10.3390/

polym13203457

Academic Editors: Fang-Chyou Chiu and Kartik Behera

Received: 9 September 2021

Accepted: 6 October 2021

Published: 9 October 2021

Publisher's Note: MDPI stays neutra with regard to jurisdictional claims in published maps and institutional affiliations.

Copyright: (c) 2021 by the authors. Licensee MDPI, Basel, Switzerland. This article is an open access article distributed under the terms and conditions of the Creative Commons Attribution (CC BY) license (https:/ / creativecommons.org/licenses/by/ $4.0 /)$
1 School of Metallurgy and Materials, University of Birmingham, Edgbaston, Birmingham B15 2TT, UK; x.li.1@bham.ac.uk (X.L.); h.dong.20@bham.ac.uk (H.D.)

2 CANOE, Le Centre Technologique Nouvelle Aquitaine Composites \& Matériaux Avancés, Bât CHEMINNOV-ENSCBP, 33600 Pessac, France; jestin@plateforme-canoe.com

3 Research Lab of Advanced, Composites, Nanomaterials and Nanotechnology (R-NanoLab), School of Chemical Engineering, National Technical University of Athens, 10682 Athens, Greece; stermine@chemeng.ntua.gr (S.T.); ktrompeta@chemeng.ntua.gr (A.-F.T.); charitidis@chemeng.ntua.gr (C.C.)

4 Materials and Composite Structures Unit, Institute of Science and Innovation in Mechanical and Industrial Engineering (INEGI), 4000-014 Porto, Portugal; aaraujo@inegi.up.pt (A.A.); rmsantos@inegi.up.pt (R.M.S.)

5 LAETA, Associate Laboratory of Energy, Transports and Aeronautics, 4000-014 Porto, Portugal

* Correspondence: z.zhang.1@bham.ac.uk

Abstract: In this work, different amounts of CNFs were added into a complex formulation to coat the CFs surfaces via sizing in order to enhance the bonding between the fibre and the resin in the CF-reinforced polymer composites. The sized CFs bundles were characterised by SEM and Raman. The nanomechanical properties of the composite materials produced were assessed by the nanoindentation test. The interfacial properties of the fibre and resin were evaluated by a push-out method developed on nanoindentation. The average interfacial shear strength of the fibre/matrix interface could be calculated by the critical load, sheet thickness and fibre diameter. The contact angle measurements and resin spreadability were performed prior to nanoindentation to investigate the wetting properties of the fibre. After the push-out tests, the characterisation via optical microscopy/SEM was carried out to ratify the results. It was found the CFs sizing with CNFs ( 1 to $10 \mathrm{wt} \%$ ) could generally increase the interfacial shear strength but it was more cost-effective with a small amount of evenly distributed CNFs on CFs.

Keywords: push-out; CNF; carbon fibre-reinforced composite; nanoindentation; contact angle

\section{Introduction}

Carbon fibre-reinforced polymer (CFRP) composites are light, strong and stiff, and they are widely used in applications requiring a high strength-to-weight ratio, such as aerospace, automotive and civil engineering, and sports equipment, etc. The interfacial properties between the fibre and the resin often significantly influence the performance of the composites, such as the failure mode and fracture toughness. Therefore, much effort is made to improve the bonding between the carbon fibres (CFs) and the matrix via physical or chemical approaches [1]. The surface of the CF is chemically inert; hence, the fibre surface modification to achieve a high specific area, good chemical activity and superior mechanical properties is critical to improve the composite interfacial properties and, ultimately, structural performance. Various techniques [2,3] are used for such purposes: (1) forming reactive functional groups on the surface of the fibres by oxidation or plasma treatment of the CF [4-6]; (2) improving the wettability of fibres by using microwaves rather than heating to cure the composite; (3) increasing reactivity and the specific surface area of CF by coating the fibres with nanoparticles (such as carbon nanotubes [7], carbon black, or graphene oxide [8]). Sizing has an easy scalability and is a widely used method in the industry to add particles to the surface of CFs and ultimately to the interface in 
CFRPs. Carbon nanotubes (CNTs) are widely used in the sizing agents for CFs to increase their bonding with the resin [9], but carbon nanofibres (CNFs) are hardly reported to be used in the sizing agents. CNFs are quasi-one-dimensional carbon materials between carbon nanotubes and CFs, with a diameter in the range from 100 to $500 \mathrm{~nm}$ and a length between 0.5 and $200 \mu \mathrm{m}$. These types of particles also have a low density, large aspect ratio, large surface area, high modulus and high strength like CNTs [10]. In this paper, the CFs' surfaces are coated with a very thin layer of a complex formulation, including CNFs via a continuous sizing procedure to examine the suitability of CNFs as a reinforcement agent. This formulation aims to boost the bond between the fibre and the resin in the final composite.

Single-fibre directly loaded and matrix externally-loaded methods are commonly used to determine the parameters of the interfacial interaction between the fibres and matrices $[11,12]$. Typically, a push-out test is carried out directly on the individual CF in the composite sample that results in the quantitative values of the interfacial shear strength (IFSS), which are directly calculated by the critical load, the sheet thickness, and the fibre diameter $[13,14]$.

In this work, the CFs bundle sized with different amounts of CNFs were observed by a scanning electron microscopy (SEM) and characterised by a Raman spectroscopy analysis. The contact angle (CA) of the resin microdroplets on the sized CFs' monofilaments was used to evaluate their wettability. The sized CFs were also used to produce pre-impregnated materials that were then converted into CFRPs in an autoclave. Nano-indentation was used to measure the nanomechanical properties, such as indentation hardness and a reduced modulus, and to carry out the push-out test. The critical loads of different CFRPs were measured and the IFSS was calculated to compare the effect of the addition of CNFs in the sizing agent. Further observations of the CFs by SEM were carried out to validate the push-out results.

\section{Experimental Details}

Bundles of 12,000 filament (12K) CFs T700 SC 31E (Toray carbon fibres Europe) were used in this work which contained an epoxy-compatible sizing agent. A sizing formulation was made of U6-01 (MICHELMAN) composed of a polymer film to bind filaments together, and a polymeric coupling agent to promote fibre-matrix interactions, and thus create strong interfaces between the fibre and matrix resin in the composite. CNFs are not soluble in water due to their inert surfaces; therefore, the non-ionic surface-active agents, Brij S20 (BS20) surfactants, were used to disperse them in aqueous media. The surfactant was a Polyethylene glycol octadecyl ether and had a molecular mass of about $1152 \mathrm{~g} / \mathrm{mol}$. The sizing content obtained was up to $2.2 \mathrm{wt} . \%$ and the nanofiller concentration in the sizing layer was between 1 and 10 wt.\%. As seen in Figure 1a, T700 SC 31 E CFs (T700), with a diameter of approximately $7 \mu \mathrm{m}$, were sized with complex formulations containing CNFs (Figure 1b), emulsifiers, anti-static agents and lubricants. A CF spool was first unwound at $5 \mathrm{~m} / \mathrm{min}$, passing in a sizing bath, and then it was squeezed into a calendar, dried using infrared (IR) light source combined with hot air, and finally collected onto another bobbin, as shown in Figure 1c.

Wettability assessment was performed on the sized CFs by two methods. In the first method, the epoxy droplet spreadability was measured. A bundle of sized CFs was attached to a flat metal substrate, grabbed from both ends, and stretched and glued onto the substrate's edges. An epoxy droplet was applied on the surface from a $4 \mathrm{~mm}$ orifice using gravity (droplet average diameter: $4.5 \mathrm{~mm}$, volume: $\sim 40 \mathrm{~mm}^{3}$ ). The spreading of the droplet on the bundles was recorded by a high-resolution video camera, and captions were taken from deposition time $\left(t_{0}\right)$ to equivalence time $\left(t_{e q}=90 \mathrm{~s}\right)$. Three measurements were performed at different points on the surface of the samples, from which the average spreading time and standard deviation were calculated. The measurements took place at room temperature, since a room temperature curing epoxy resin was used, with a low viscosity. For the quantification of the spreading time (by measuring the length of 
the spreading droplet), the Image J software was used. In the second method, the CA of microdroplets was measured in order to detect differences in the microscale. One monofilament was selected and isolated from the CF bundle and, with the help of scotch tape, it was then attached to a plexiglass holder, under tension. Microdrops (30-200 $\mu \mathrm{m}$ in diameter) of epoxy resin were placed on the monofilaments, using a micro-syringe. For statistical reasons, only microdrops $40-60 \mu \mathrm{m}$ in diameter were used to measure up to 10 monofilaments. Images for each specimen were captured through optical microscopy using a Zeiss Axio Imager A2.m microscope at the moment of placement, in order to measure the average CA [15]. A schematic representation of the assembly is shown in Figure 2.

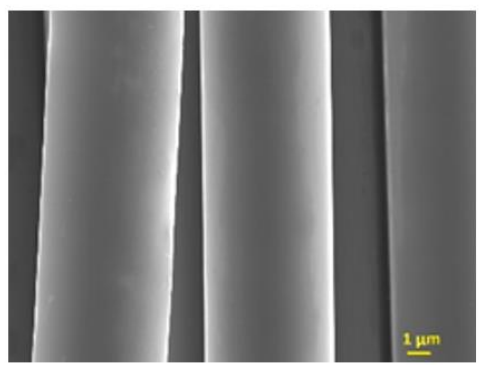

(a)

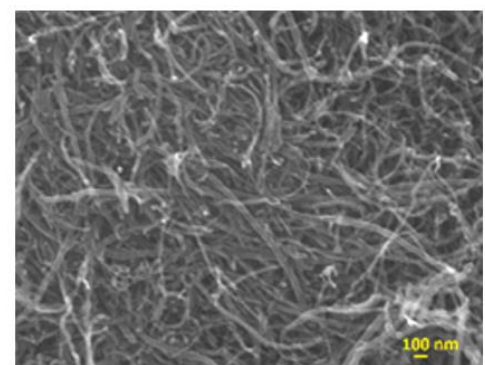

(b)

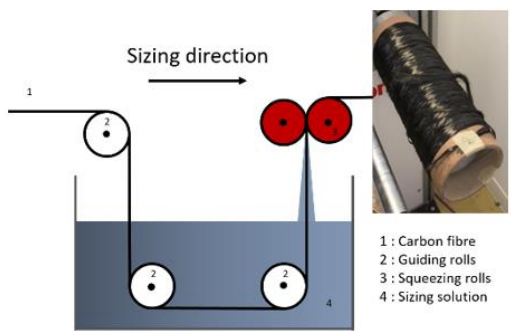

(c)

Figure 1. (a) T700 CFs, (b) CNFs and (c) the sizing process.

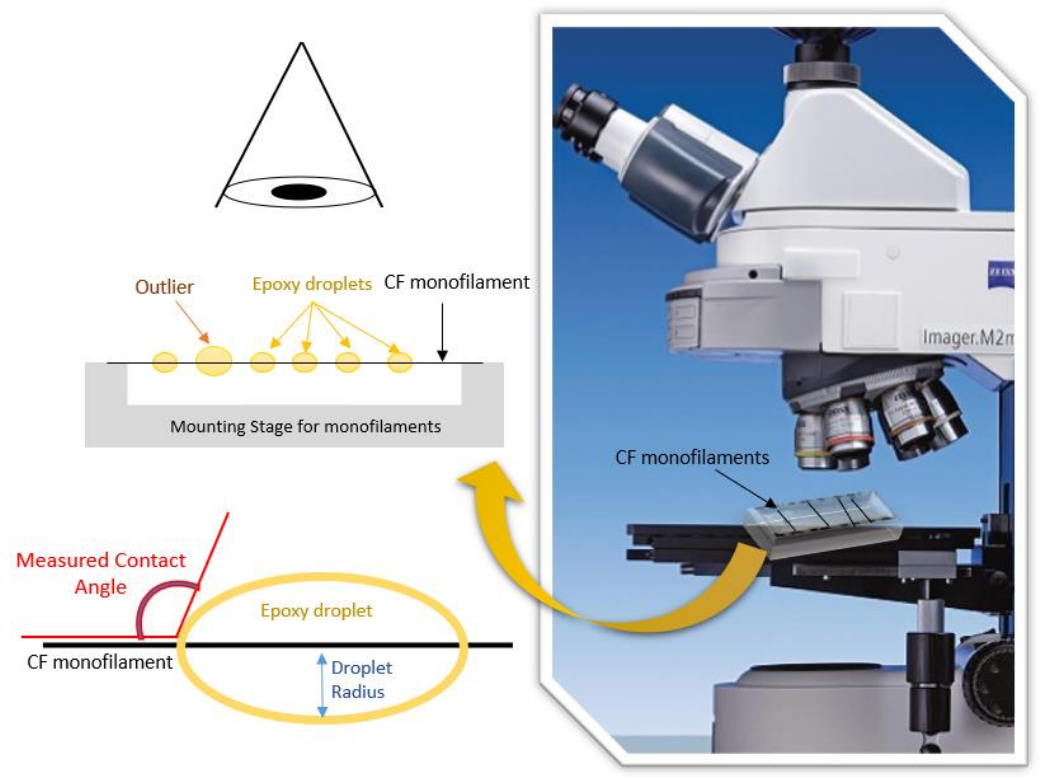

Figure 2. Contact angle measurement on CF monofilaments.

The sized CFs were combined with a resin system composed of a diglycidyl ether of bisphenol A (DGEBA, Araldite LY 1556), Aradur 1571, accelerator 1573 and hardener XB 3403 (100:23:5:12 ratio) from Huntsman Advanced Materials ${ }^{\circledR}$ (Bergkamen, Germany), to prepare pre-impregnated materials. Afterwards, the prepreg sheets were cut into sections 
and converted into CFRP composites with 10 plies, using an autoclave at $120^{\circ} \mathrm{C}$ and $3.5 \mathrm{bar}$ for $2 \mathrm{~h}$. The $\mathrm{CF}$ volume fraction $\left(\mathrm{V}_{\mathrm{CF}}\right)$ of the CFRPs produced was determined according to ASTM D3171 and the results are presented in Table 1.

Table 1. Detail of sizing of T700 CFs with CNFs and CF volume fraction of the respective CFRPs.

\begin{tabular}{ccccc}
\hline Code & Surfactant & \% Sizing & \% Filler in Sizing & CFRPs V \\
\hline T700 & - & - & - & 51 \\
\hline U1F1 & BS20 & 2.4 & $1 \%$ CNF & 56 \\
\hline U5F1 & BS20 & 1.4 & $5 \%$ CNF & 51 \\
\hline U10F1 & BS20 & 1.8 & $10 \%$ CNF & 56 \\
\hline
\end{tabular}

A Micro Materials NanoTest system was used for the nanoindentation and push-out tests. The CFRPs were mounted in bakelite and polished to mirror-like surface for nanohardness measurements. Afterwards, they were cut to obtain a thin slice with a thickness less than $1 \mathrm{~mm}$. The slice was then broken into a few small pieces by a sharp blade to obtain the CFRP piece (Figure 3a). The polished side of the small piece was attached to an aluminium stud and ground progressively by 1200,2500 and 4000 grit sandpapers to under $100 \mu \mathrm{m}$ thick, followed by polishing with colloidal silica suspension on a Struers MD-Chem napped cloth. The thicknesses of the final specimens were between 10-60 $\mu \mathrm{m}$. The polished specimen was stuck to a rectangle holder with laser machined grooves with a width of $30 \mu \mathrm{m}$ and a depth of $12 \mu \mathrm{m}$, and then glued to the standard cylinder support (Figure 3b). A specially made cone-shaped indenter was used in the push-out test and the round indentation and the laser-machined groove can be seen in Figure 3c. The cone shape ensures an even load and contact with the fibre when compared to a sharp-edged standard Berkovich indenter. The maximum effective depth (L) was about $2.2 \mu \mathrm{m}$ for a fibre of $7 \mu \mathrm{m}$ in diameter before the cone contact with the surrounding resin (Figure 3e). The push-out experiments were conducted in an environmental enclosure controlled at $20.0 \pm 1.0^{\circ} \mathrm{C}$.

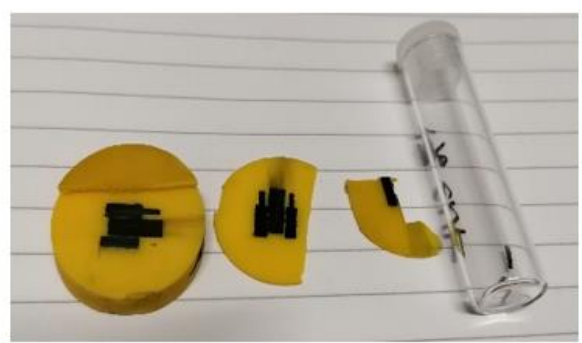

(a)

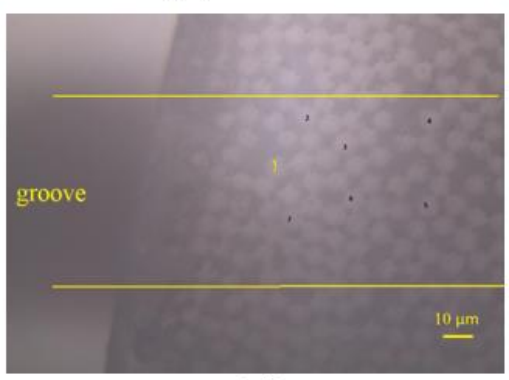

(d)

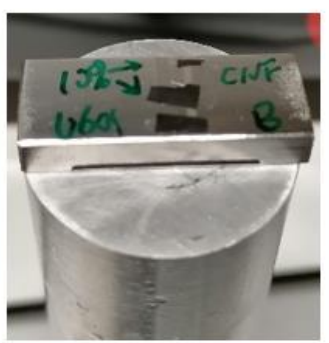

(b)

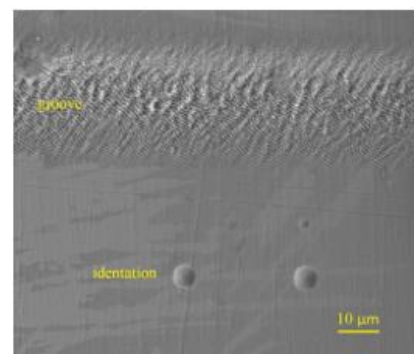

(c)

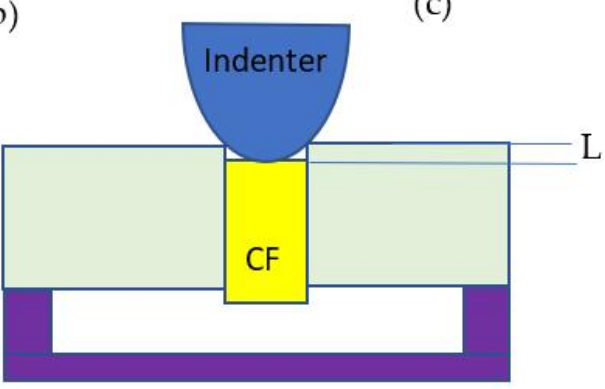

(e)

Figure 3. Composite specimen preparation (a) pieces cut from mounted samples, (b) specimens mounted on the sample holder, (c) the round indentations and the groove, (d) optical microscopy image of the specimen, and (e) schematic of push-out test.

Firstly, in the push-out test, a suitable area on top of the groove (between the two lines) was selected (Figure 3d) and the thickness of the specimen was measured by recording 
the distance change in the focus from the flat area of the holder to the specimen surface. Secondly, the individual CF, i.e., CF 1, was identified under optical microscopy (Figure 3d). Then, a load was gradually applied to each individual location using the diamond indenter in sequence from an initial load of $10 \mu \mathrm{N}$ to a maximum peak load at a loading rate of $1 \mathrm{mN} / \mathrm{s}$ (Figure 3e). The peak load was greater than the critical load and was decided experimentally for each specimen. The average interfacial shear strength (IFSS) at the fibre/matrix interface is provided by [14]:

$$
I F S S=\frac{P}{2 \pi r e}
$$

where $P$ is the applied critical load, $r$ is the fibre radius, and $e$ is the sheet thickness. After all the fibres were tested, the fibres in the composite were observed via the onsite microscopy or by a JEOL7000 SEM after unloading from the holder to validate the experiment. The push-out test was carried out at different places with different thicknesses to achieve accurate results.

\section{Results and Discussion}

\subsection{Carbon Fibres after Sizing CNFs}

The unsized CFs' surface was smooth and clean without any defects (Figure 1a). After $\mathrm{CNFs}$ sizing, the surfaces of the CFs were smooth and even (Figure $4 \mathrm{a}, \mathrm{c}, \mathrm{e}$ ). For sample U1F1, the CNFs were sparsely distributed on the surface (Figure $4 \mathrm{~b}$ ). When the amount of CNFs in the sizing agents increased, more CNFs were incorporated into the sizing layer of the CFs, as seen in Figure $4 \mathrm{~d}$,f. As can be seen in the Raman spectroscopy in Figure 5, G $\left(1595 \mathrm{~cm}^{-1}\right)$ and $D\left(1367 \mathrm{~cm}^{-1}\right)$ peaks can be identified on the surface of the sized CFs. With the absorbing of $5-10 \%$ CNFs on the surface peaks, $2 \mathrm{D}$ can also be found at $\left(2722 \mathrm{~cm}^{-1}\right)$.

\subsection{Wettability Assessment of CNF-Sized CFs}

The epoxy droplets spreading on the CNF-based sized bundles of various concentrations are shown in Figure 6. The specimen with $5 \mathrm{wt}$ \% CNFs (U5F1) had a similar behaviour to the commercial sizing until $60 \mathrm{~s}$ of spreading, with a slight increase in the deposited droplet at the same time. After $60 \mathrm{~s}$ the results showed a sharp increase in spreading. The specimen with a sizing of $10 \mathrm{wt} \% \mathrm{CNFs}$ (U10F1) showed the highest rate of spreading for the first $40 \mathrm{~s}$, reaching a plateau afterwards. The lowest CNF concentration sizing ( $1 \mathrm{wt} . \%$ CNFs-U1F1) showed a linear spreading behaviour, with the lowest rate of all the samples tested, indicating that a high affinity was achieved with the epoxy resin.

According to the spreadability results, it was decided to proceed with single-fibre wettability testing to detect differences in the microscale. The optical images taken on single fibres are shown in Figure 7 and the average CAs are presented in Table 2.

The micro-droplets on the pristine fibre presented a CA of $114.8^{\circ}$ whereas, on the sized CFs with $1 \mathrm{wt} . \% \mathrm{CNFs}$, significantly larger CAs $\left(163.9^{\circ}\right)$ were measured, indicating the improvement in the wetting properties of the fibres. An improvement in the wettability was also evident for the $10 \mathrm{wt} . \%$ CNFs sizing. On the other hand, $5 \mathrm{wt} . \%$ CNFs only slightly changed the wetting properties of the fibres in static conditions, which was in accordance with the results of the spreadability testing for the first seconds of measurements. 


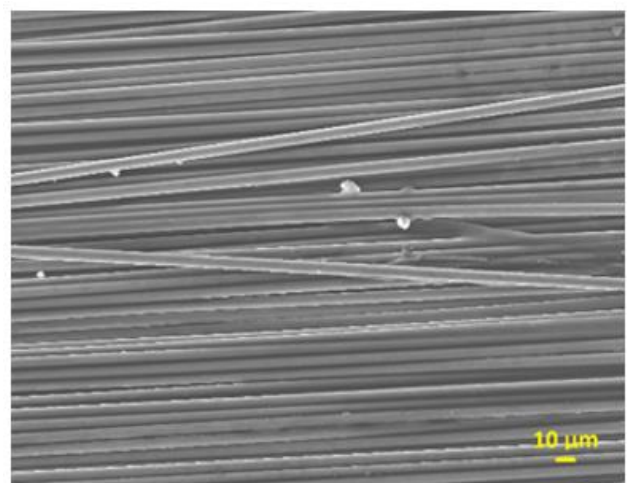

(a)

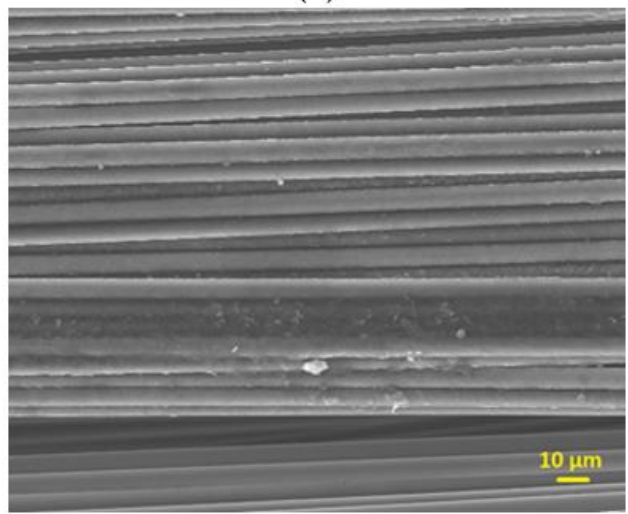

(c)

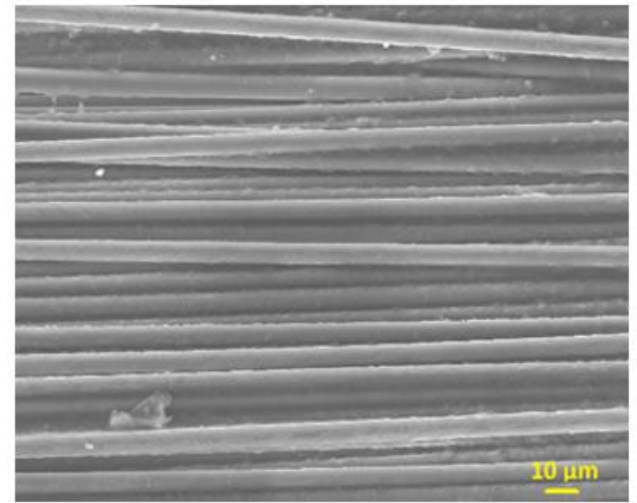

(e)

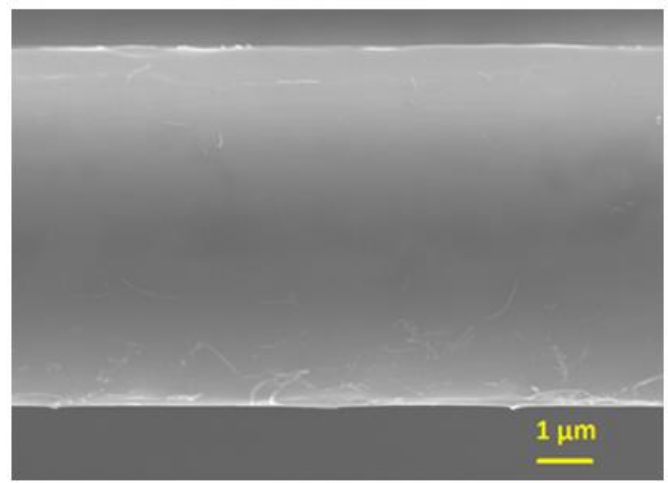

(b)

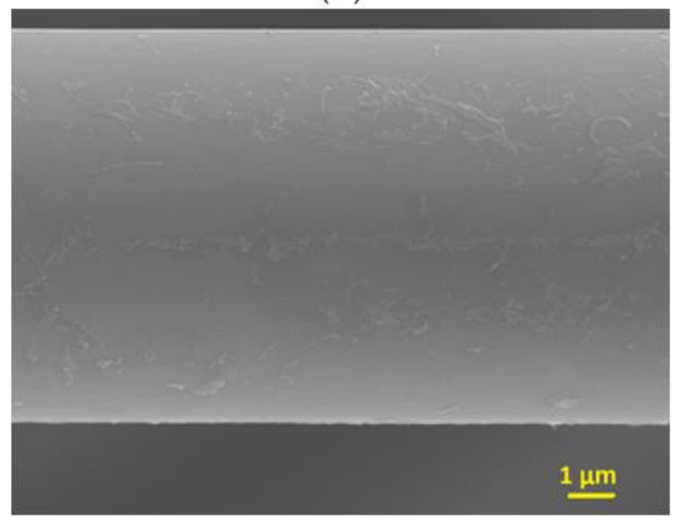

(d)

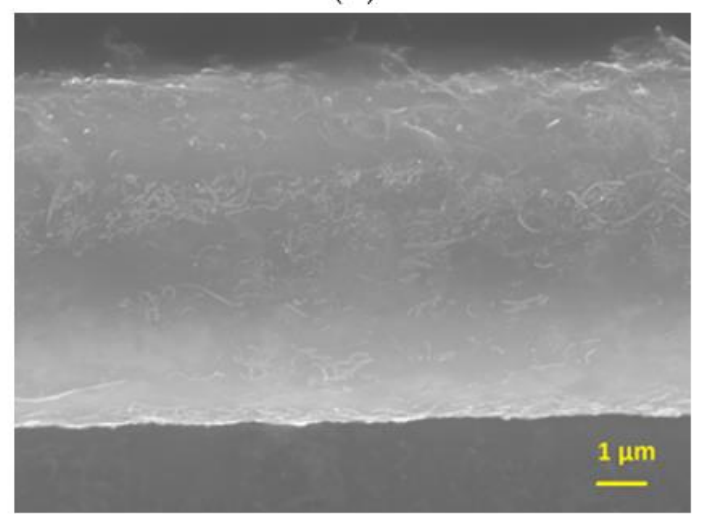

(f)

Figure 4. T700 CFs with CNFs in sizing agent (a,b) $1 \%$ CNFs, (c,d) $5 \%$ CNFs (e,f) $10 \%$ CNFs.

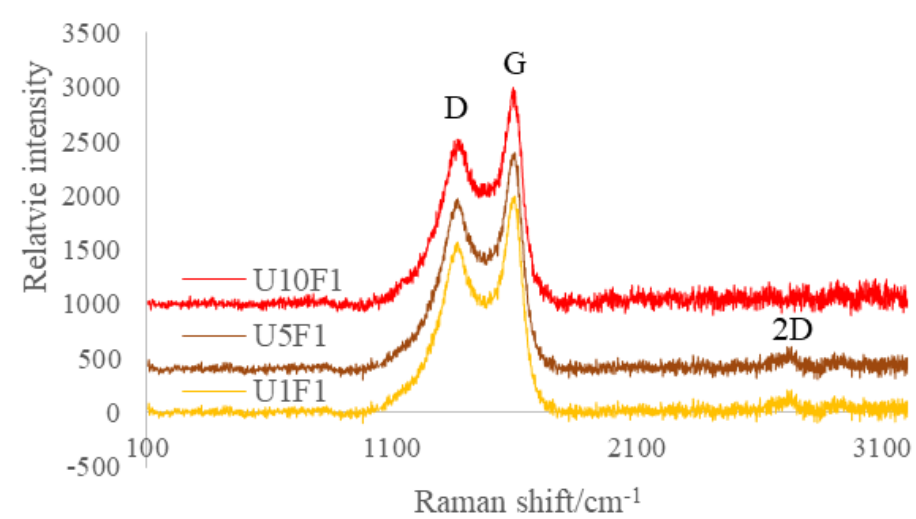

Figure 5. Surface chemistry analyses by Raman on CFs sized with different amount of CNFs. 


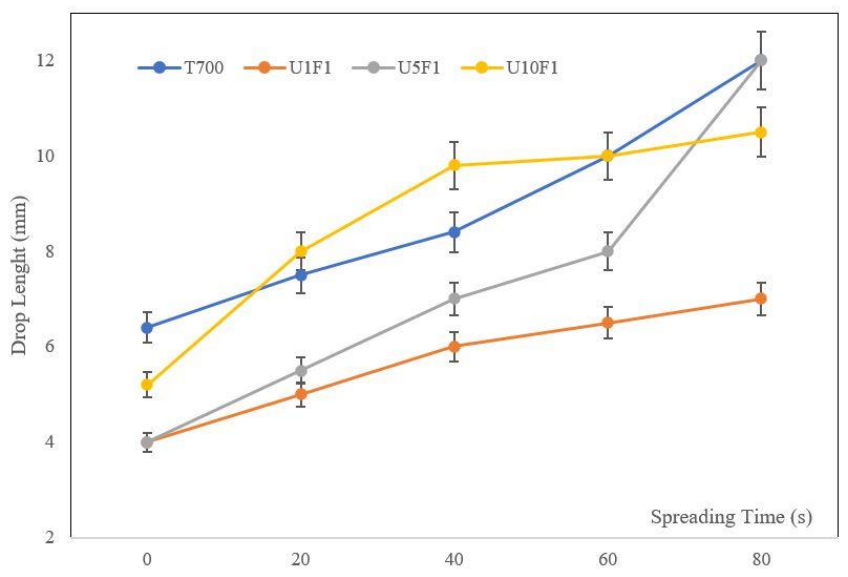

Figure 6. Spreadabillity testing on CNF-based sized CF bundles.

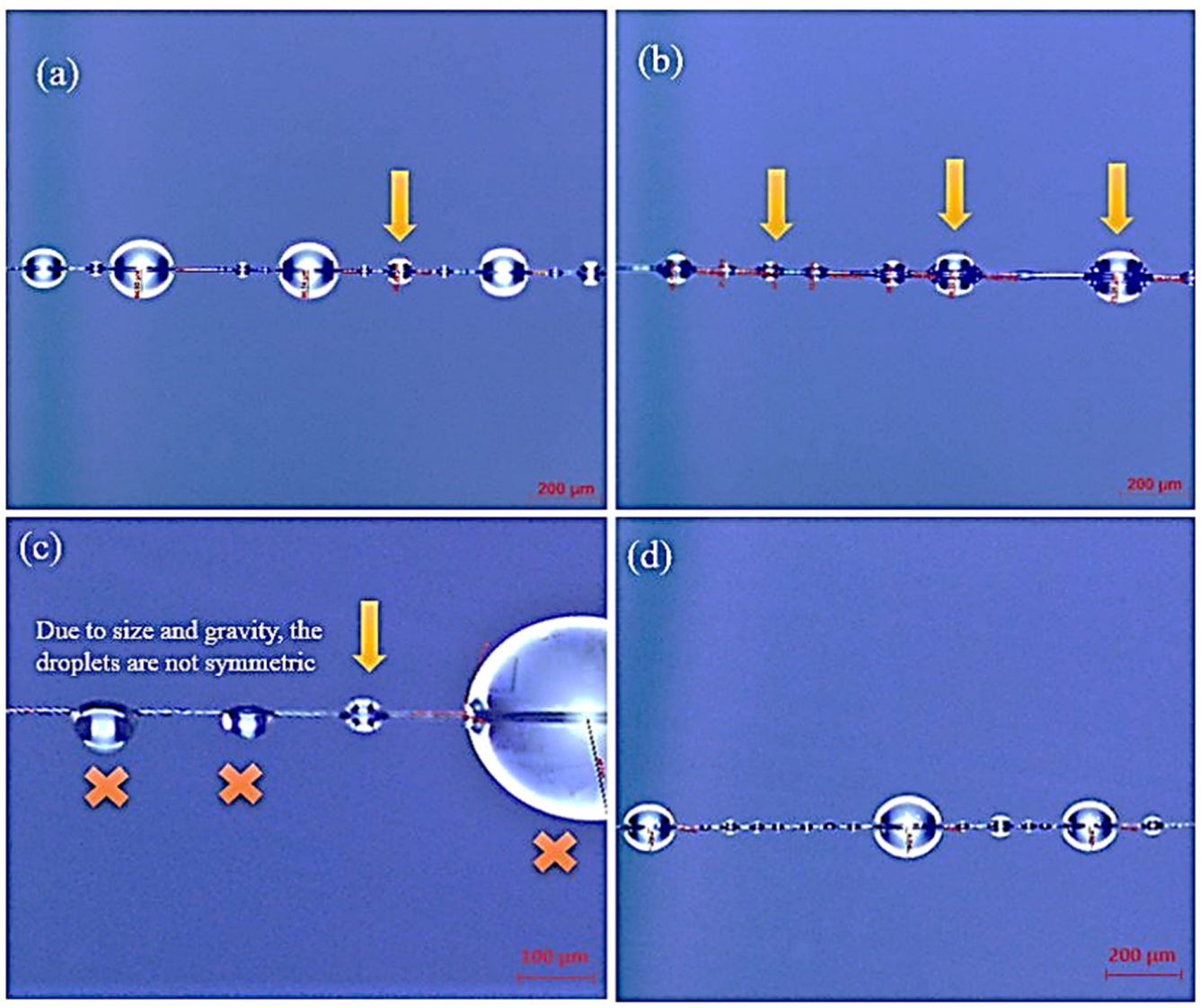

Figure 7. Contact angle measurements of CNF sized fibres with different wt.\%: (a) T700 (reference), (b) 1 wt.\% CNF-U1F1, (c) 5 wt.\% CNF-U5F1 and (d) 10 wt.\% CNF-U10F1.

Table 2. Average measured contact angles and average diameter of the measured micro-droplets.

\begin{tabular}{cccc}
\hline Code & Droplet Radius $(\mu \mathrm{m})$ & Contact Angle (deg) & Results \\
\hline T700 & $52.6 \pm 5.4$ & $114.8 \pm 2.3$ & Reference Value \\
\hline U1F1 & $44.3 \pm 9.2$ & $163.9 \pm 7.8$ & Highly Improved \\
\hline U5F1 & $58.1 \pm 3.6$ & $120.3 \pm 3.6$ & Slightly improved \\
\hline U10F1 & $45.2 \pm 7.2$ & $127.3 \pm 5.2$ & Improved \\
\hline
\end{tabular}




\subsection{Nanomechanical Properties of the CFRPs}

A mapping nanoindentation test was carried out to measure the nanomechanical properties of the CFRPs. After the examination of the indentations via microscopy and the corresponding of the indentations to the $\mathrm{CFs}$, the resin, interfaces, hardness and reduced elastic modulus can be calculated; the results of the T700 reinforced composites are shown in Figure 8. CFs have a much higher nano-hardness and reduced modulus than those of the resin. Meanwhile, the hardness and elastic modulus changes gradually at the interface between the CFs and the resin depending on the location of the indentation, which ensures the high-strength carbon fibre reinforces the relatively low-strength resin to obtain the desired properties of the composite materials. There is no significant change in the results measured for the sized CFs with the CNF-reinforced composites; therefore, a more precise method such as the push-out method needs to be used to assess the impact of the addition of CNFs to the interfacial properties.

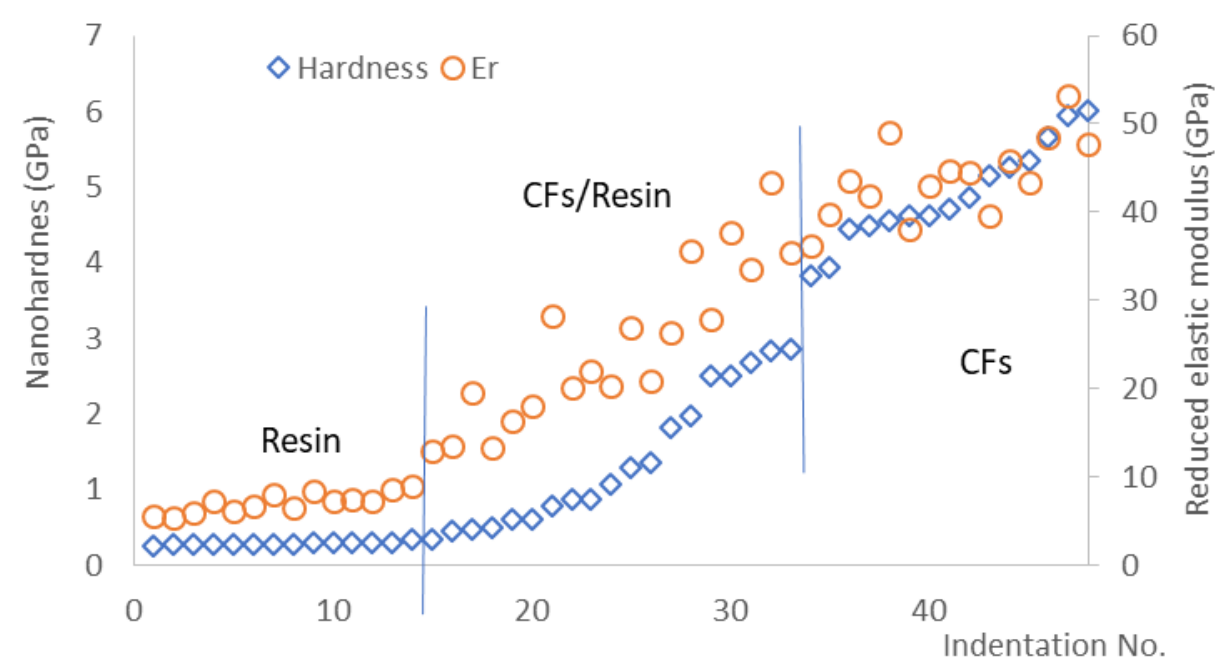

Figure 8. Nano-hardness $(\mathrm{H})$ and reduced elastic modulus $(\mathrm{Er})$ of sized CFs and resin in the composite measured under a load of $5 \mathrm{mN}$ (T700).

\subsection{Push-Out Test}

As shown in Figure 9a, the individual CFs were first identified with an on-site microscope, and then the push-out test was carried out on them in sequence. The typical load vs. displacement curves of selected CFs can be seen in Figure 9c. There was a short initial non-linear stage until a conformal contact was reached between the indenter, the specimen and the supporting plate, especially when followed by a linear elastic region (Figure 9c).

As the load increased to a certain level, a constant load with an increased displacement was reached, which corresponded to the debonding of the fibre, and this was the critical load (P). Observations on the fibres after the push-out test by the on-site optical microscopy and post observation using SEM could validate the results (Figure 9b). For the corresponding curves and indentations analysis, six fibres were used to calculate the interfacial shear strength (Figure 9c). However, fibre 4 strongly interfered with the neighbouring fibres and was not included in the statistics. The corresponding critical load and calculated IFSS are shown in Figure 9d for sample T700. 


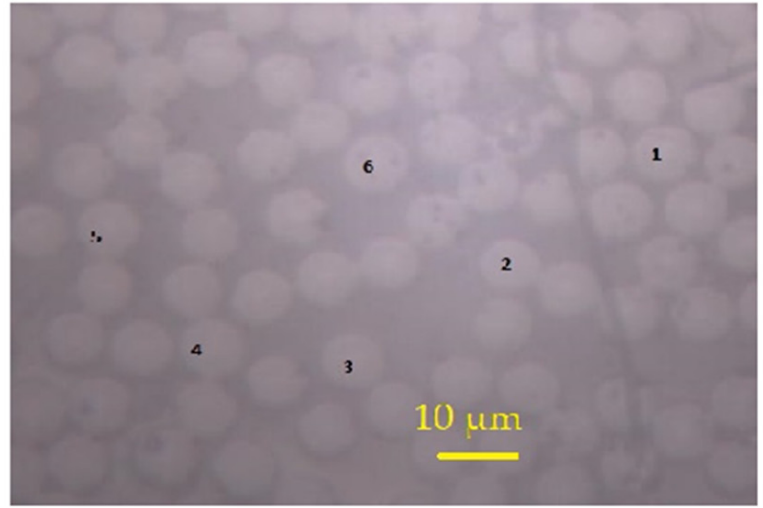

(a)

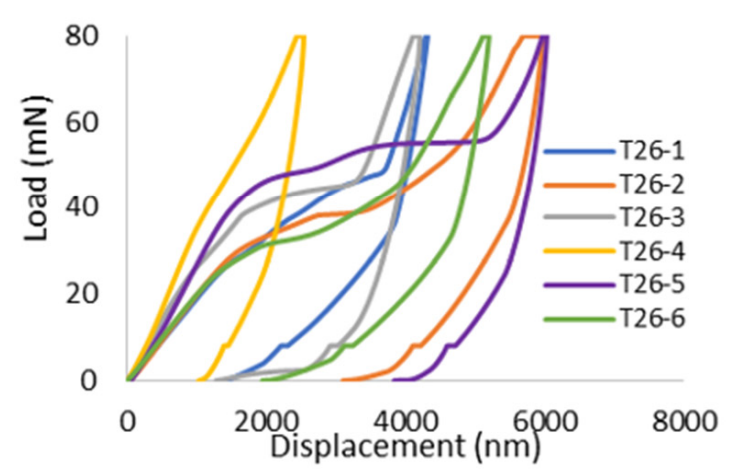

(c)

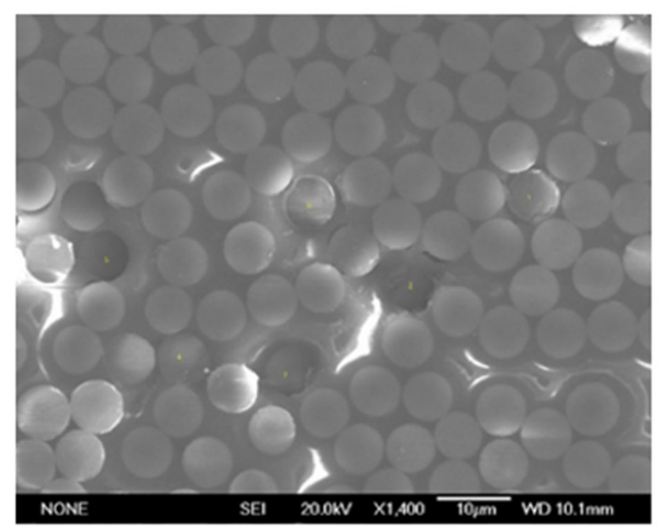

(b)

\begin{tabular}{|c|c|c|}
\hline Code & Critical load (mN) & IFSS (Mpa) \\
\hline T26-1 & 34 & 60 \\
\hline T26-2 & 32 & 56 \\
\hline T26-3 & 40 & 70 \\
\hline T26-5 & 44 & 77 \\
\hline T26-6 & 31 & 54 \\
\hline Average & $36 \pm 7$ & $63 \pm 14$ \\
\hline
\end{tabular}

(d)

Figure 9. The carbon fibres in a $26 \mu \mathrm{m}$ (T26) thick T700-31E specimen (a) before and (b) after push-out test, (c) load vs. displacement curves, and (d) the critical load and the relevant IFSS.

For the sample U10F1 (sizing with 10\% CNFs), different areas of the samples with varied thicknesses were tested. Generally, the edge of the specimen was thinner, and it became thicker with the move to the centre of the specimen, as seen in Figure 10a. The corresponding critical load and calculated IFSS with different thicknesses $(31 \mu \mathrm{m}, 33 \mu \mathrm{m}$ and $42 \mu \mathrm{m}$ ) are shown in Figure $7 \mathrm{~b}$. It can be seen that the critical load increases with the thickness of the specimen; however, the IFSS only changes slightly with the thickness. Nine tests on a total of $77 \mathrm{CF}$ s were conducted and the average IFSS was $72 \pm 9 \mathrm{MPa}$.

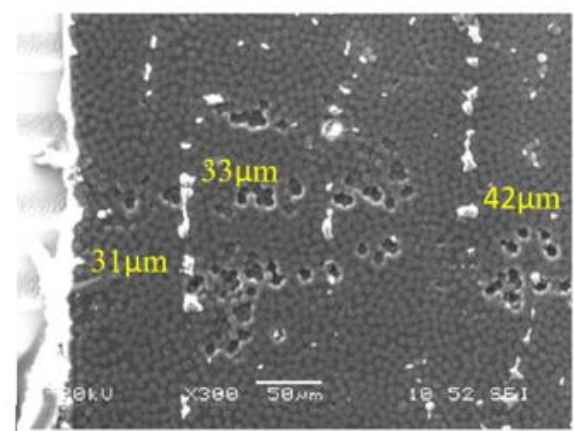

(a)

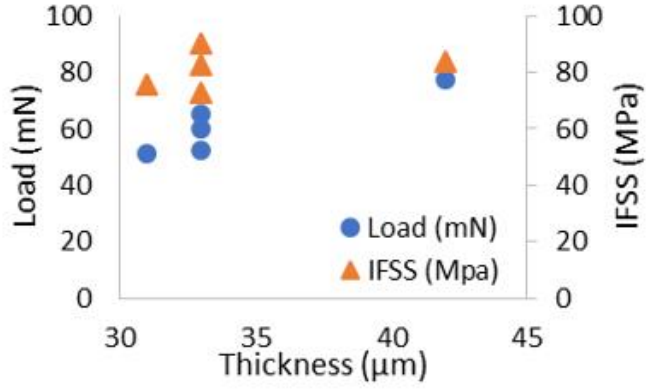

(b)

Figure 10. Sample U10F1: (a) the area for push-out test with different thicknesses (b) the critical load and the relevant IFSS with different thicknesses.

Figure 11 presents a comparison of the IFSS results obtained for the reinforced epoxy resin with different-sized CFs. Ten tests were carried out on a total of ninety-four CFs 
to measure the critical loads at different thickness for the unsized T700 sample, and the average IFSS was about $61 \pm 4 \mathrm{MPa}$. The IFSS increased for all the samples sized with the addition of CNFs, and U1F1 presented the most significant result of the $74 \pm 4 \mathrm{MPa}$ which corresponded to an increase of $21.3 \%$ (15 tests on $82 \mathrm{CFs}$ ). However, the increased IFSS for U5F1 with a $5 \mathrm{wt}$.\% addition of CNFs (7 tests on $54 \mathrm{CFs)}$ was even lower than that of U10F1. This might be because the values were obtained from a thinner sample $(<30 \mu \mathrm{m})$ which might lead to an easier move from the CFs, and the smaller amount of sizing content (1.4 wt.\%) might also contribute to it (Table 1). The other reason might be due to some agglomeration of CNFs on the CFs which negatively affect the bond between the CFs and resin, which has been reported earlier [9].

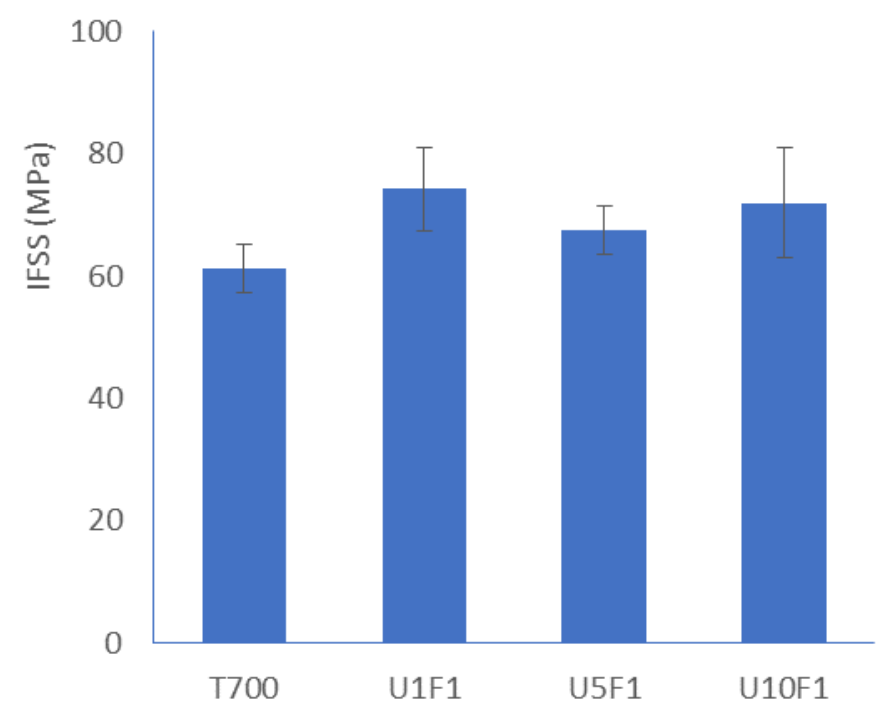

Figure 11. Comparison of the interfacial shear strength with different specimen thickness of the sized carbon fibres in CFRP.

As previously mentioned, CNFs generally had a larger diameter and length than CNTs; therefore, they were seldom used in sizing agents. However, in this work, it was found that the addition of CNFs in the sizing agent generally had a positive effect on the interfacial strength. The higher amount of added CNFs, aside from not being cost effective, did not lead to a proportional increase in the IFSS. Furthermore, high amounts of carbon nano-inclusions tended to cause local agglomeration (Figure 4c-e), which was unfavourable for the improvement of interfacial properties [9].

In short, the sizing agents played a leading role to enforce the compatibility between the CFs and the resin in the composite. The resin droplet remained consistent and took a longer time to spread, which was helpful to prevent interfacial slip. Therefore, the affinity with the matrix was stronger, and the smaller amounts of CNFs could significantly improve the interfacial properties in CFRPs. Furthermore, the agents could cover the CFs smoothly and evenly to avoid agglomeration, which negatively influenced the interfacial strength. In comparison with other carboneous nano-inclusions (Table 3), the sizing with the inclusion of CNFs only showed an approximate increase of $20 \%$ in the IFSS. Nevertheless, this method normally introduced less damage to the CFs, was simple to operate and easy to scale-up, and could be conveniently incorporated into current production line, making it generally more attractive than other approaches. 
Table 3. Carbonaceous materials coated CFs to enhance their IFSS [3].

\begin{tabular}{|c|c|c|c|}
\hline Nano Inclusions & Method & IFSS Increase & Potential Issues \\
\hline \multirow{3}{*}{ CNTs } & $\begin{array}{l}\text { Dip-coating [16] and } \\
\text { Electphoretic } \\
\text { deposition [17] }\end{array}$ & $14-33 \%$ & $\begin{array}{l}\text { Agglomeration, dispersion } \\
\text { issue, and solution } \\
\text { damage to CFs }\end{array}$ \\
\hline & CVD [18] & $94 \%$ & $\begin{array}{c}\text { Thermal degradation and } \\
\text { catalyst diffusion }\end{array}$ \\
\hline & Sizing $(0.1 \% C N T)[9]$ & $97.6 \%$ & Agglomeration \\
\hline Graphene nanoplates & $\begin{array}{l}\text { Microwave enhanced } \\
\text { plasma CVD [19] }\end{array}$ & $101.5 \%$ & $\begin{array}{l}\text { High-temperature } \\
\text { treatment }\left(600^{\circ} \mathrm{C}\right) \text { and } \\
\text { vacuum required }\end{array}$ \\
\hline Graphene oxide & $\begin{array}{l}\text { Chemical Grafting [20], } \\
\text { Electrophoretic deposition } \\
\text { and dip coating [16] }\end{array}$ & $11-69.9 \%$ & $\begin{array}{l}\text { Exposure to an electric } \\
\text { field in } \\
\text { solution } \rightarrow \text { reduction in } \\
\text { CFs strength }\end{array}$ \\
\hline Carbon black & $\mathrm{CVD}$ at $1000^{\circ} \mathrm{C}$ [21] & $44 \%$ & $\begin{array}{l}\text { Thermal degradation } \\
\text { and high } \\
\text { temperature required. }\end{array}$ \\
\hline CNFs & $\begin{array}{c}\text { Electro-spinning } \\
\text { grafting [22] } \\
\text { O-CNFs by Electrophoretic } \\
\text { deposition (EPD) [23] }\end{array}$ & $48 \%$ & $\begin{array}{l}\text { Hybridization and } \\
\text { exposure to an electric } \\
\text { field in solution could } \\
\text { damage the CFs }\end{array}$ \\
\hline
\end{tabular}

\section{Conclusions}

Commercial CFs surfaces were coated with a very thin layer of a complex formulation, including different amounts of CNFs via sizing, which aimed to create strong interfaces between the fibre and the resin. Nano-indentation was used to measure the mechanical properties and assess the interfacial shear strength of the CFs and resin through a pushout test. In the experiment, an individual CF started to slide under a critical load which could be used to calculate the interfacial shear strength (IFSS). Although the CNFs had larger dimensions than the CNTs, the addition of CNFs in the sizing agent could generally increase the bond between the CFs and resin, especially with a lower filler amount of $1 \mathrm{wt} \%$. The same also applied for the wettability of the fibres in the microscale, where the $1 \mathrm{wt} \%$ of $\mathrm{CNFs}$ in the sizing solution presented a high improvement of the wettability. However, sizing with a larger number of CNFs proved to be a less cost-effective approach, since it did not lead to a proportionate increase in the IFSS.

Author Contributions: Conceptualization, Z.Z.; methodology, Z.Z.; validation, Z.Z., X.L. and A.-F.T.; formal analysis, Z.Z. and A.-F.T.; investigation, Z.Z., S.J. and S.T.; resources, Z.Z. and R.M.S.; data curation, Z.Z., S.J. and S.T.; writing—original draft preparation, Z.Z.; writing-review and editing, Z.Z., A.-F.T., A.A.; supervision, H.D.; project administration, C.C.; funding acquisition, H.D. and C.C. All authors have read and agreed to the published version of the manuscript.

Funding: This research was funded by the EU H2020 Project 'Smart by Design and Intelligent by Architecture for turbine blade fan and structural components systems' (SMARTFAN) under Grant no. 760779 .

Institutional Review Board Statement: Not applicable.

Informed Consent Statement: Not applicable.

Data Availability Statement: Data is contained within this article.

Conflicts of Interest: The authors declare no conflict of interest. The funders had no role in the design of the study; in the collection, analyses, or interpretation of data; in the writing of the manuscript, or in the decision to publish the results. 


\section{References}

1. Farooq, U.; Teuwen, J.; Dransfeld, C. Toughening of Epoxy Systems with Interpenetrating Polymer Network (IPN): A Review. Polymers 2020, 12, 1908. [CrossRef] [PubMed]

2. Florek, P.; Król, M.; Jeleń, P.; Mozgawa, W. Carbon Fiber Reinforced Polymer Composites Doped with Graphene Oxide in Light of Spectroscopic Studies. Materials 2021, 14, 1835. [CrossRef] [PubMed]

3. Salahuddin, B.; Faisal, S.N.; Baigh, T.A.; Alghamdi, M.N.; Islam, M.S.; Song, B.; Zhang, X.; Gao, S.; Aziz, S. Carbonaceous Materials Coated Carbon Fibre Reinforced Polymer Matrix Composites. Polymers 2021, 13, 2771. [CrossRef] [PubMed]

4. Liang, Y.; Li, X.; Semitekolos, D.; Charitidis, C.A.; Dong, H. Enhanced properties of PAN-derived carbon fibres and resulting composites by active screen plasma surface functionalisation. Plasma Process. Polym. 2020, 17, 1900252. [CrossRef]

5. Corujeira Gallo, S.; Charitidis, C.; Dong, H. Surface functionalization of carbon fibers with active screen plasma. J. Vac. Sci. Technol. A 2017, 35, 021404. [CrossRef]

6. Khan, A.; Dragatogiannis, D.; Jagdale, P.; Rovere, M.; Rosso, C.; Tagliaferro, A.; Charitidis, C. Novel carbon fibers synthesis, plasma functionalization, and application to polymer composites. Express Polym. Lett. 2021, 15, 361-374. [CrossRef]

7. Termine, S.; Trompeta, A.-F.A.; Dragatogiannis, D.A.; Charitidis, C.A. Novel CNTs grafting on carbon fibres through CVD: Investigation of epoxy matrix/fibre interface via nanoindentation. MATEC Web Conf. 2019, 304, 01014. [CrossRef]

8. Zeng, L.; Liu, X.; Chen, X.; Soutis, C. $\pi-\pi$ interaction between carbon fibre and epoxy resin for interface improvement in composites. Compos. Part B: Eng. 2021, 220, 108983. [CrossRef]

9. Liu, Y.-t.; Li, L.; Wang, J.-p.; Fei, Y.-j.; Liu, N.-d.; Wu, G.-p. Effect of carbon nanotube addition in two sizing agents on interfacial properties of carbon fiber / polycarbonate composites. New Carbon Mater. 2021, 36, 639-648. [CrossRef]

10. Han, B.; Yu, X.; Ou, J. Chapter 5-Sensing Properties of Self-Sensing Concrete. In Self-Sensing Concrete in Smart Structures; Han, B., Yu, X., Ou, J., Eds.; Butterworth-Heinemann: Oxford, UK, 2014; pp. 95-162. [CrossRef]

11. Zhandarov, S.; Mäder, E. Characterization of fiber/matrix interface strength: Applicability of different tests, approaches and parameters. Compos. Sci. Technol. 2005, 65, 149-160. [CrossRef]

12. Huang, S.; Fu, Q.; Yan, L.; Kasal, B. Characterization of interfacial properties between fibre and polymer matrix in composite materials-A critical review. J. Mater. Res. Technol. 2021, 13, 1441-1484. [CrossRef]

13. Zhang, Z.; Gallo, S.C.; Li, X.; Dong, H.; Dragatogiannis, D.; Charitidis, C.A. Evaluation of the creep behaviour of the carbon fibre in an unidirectional pultruded reinforced composite using nano-indentation technique. Polym. Test. 2019, 80, 106091. [CrossRef]

14. Corujeira Gallo, S.; Li, X.; Zhang, Z.; Charitidis, C.; Dong, H. Viscoelastic response of carbon fibre reinforced polymer during push-out tests. Compos. Part A Appl. Sci. Manuf. 2018, 112, 178-185. [CrossRef]

15. Semitekolos, D.; Kainourgios, P.; Jones, C.; Rana, A.; Koumoulos, E.P.; Charitidis, C.A. Advanced carbon fibre composites via poly methacrylic acid surface treatment; surface analysis and mechanical properties investigation. Compos. Part B Eng. 2018, 155, 237-243. [CrossRef]

16. Hung, P.-y.; Lau, K.-t.; Fox, B.; Hameed, N.; Lee, J.H.; Hui, D. Surface modification of carbon fibre using graphene-related materials for multifunctional composites. Compos. Part B Eng. 2018, 133, 240-257. [CrossRef]

17. De, S.; Fulmali, A.O.; Nuli, K.C.; Prusty, R.K.; Prusty, B.G.; Ray, B.C. Improving delamination resistance of carbon fiber reinforced polymeric composite by interface engineering using carbonaceous nanofillers through electrophoretic deposition: An assessment at different in-service temperatures. J. Appl. Polym. Sci. 2021, 138, 50208. [CrossRef]

18. An, F.; Lu, C.; Li, Y.; Guo, J.; Lu, X.; Lu, H.; He, S.; Yang, Y. Preparation and characterization of carbon nanotube-hybridized carbon fiber to reinforce epoxy composite. Mater. Des. 2012, 33, 197-202. [CrossRef]

19. Karakassides, A.; Ganguly, A.; Tsirka, K.; Paipetis, A.S.; Papakonstantinou, P. Radially Grown Graphene Nanoflakes on Carbon Fibers as Reinforcing Interface for Polymer Composites. ACS Appl. Nano Mater. 2020, 3, 2402-2413. [CrossRef]

20. Zhang, R.L.; Gao, B.; Ma, Q.H.; Zhang, J.; Cui, H.Z.; Liu, L. Directly grafting graphene oxide onto carbon fiber and the effect on the mechanical properties of carbon fiber composites. Mater. Des. 2016, 93, 364-369. [CrossRef]

21. Dong, J.; Jia, C.; Wang, M.; Fang, X.; Wei, H.; Xie, H.; Zhang, T.; He, J.; Jiang, Z.; Huang, Y. Improved mechanical properties of carbon fiber-reinforced epoxy composites by growing carbon black on carbon fiber surface. Compos. Sci. Technol. 2017, 149, 75-80. [CrossRef]

22. Hong, S.; Minary-Jolandan, M.; Naraghi, M. Controlling the wettability and adhesion of carbon fibers with polymer interfaces via grafted nanofibers. Compos. Sci. Technol. 2015, 117, 130-138. [CrossRef]

23. Schaefer, J.D.; Rodriguez, A.J.; Guzman, M.E.; Lim, C.-S.; Minaie, B. Effects of electrophoretically deposited carbon nanofibers on the interface of single carbon fibers embedded in epoxy matrix. Carbon 2011, 49, 2750-2759. [CrossRef] 